\title{
The University Patent Evaluation System Model and Application Countermeasures
}

\author{
Dan $\mathrm{Li}^{1}$, Long Cheng ${ }^{2}$ \\ ${ }^{1}$ Intellectual Property Research Center of Jiangsu Province, Jiangsu University, Zhenjiang, China \\ ${ }^{2}$ Jiangsu Huizhi Intellectual Property Services Limited, Zhenjiang, China
}

Email address:

lidan@ujs.edu.cn (Dan Li), chenglong@jshzip.com (Long Cheng)

To cite this article:

Dan Li, Long Cheng. The University Patent Evaluation System Model and Application Countermeasures. European Business \& Management. Vol. 3, No. 6, 2017, pp. 127-133. doi: 10.11648/j.ebm.20170306.16

Received: November 15, 2017; Accepted: December 11, 2017; Published: December 26, 2017

\begin{abstract}
With the number of patents continue to accumulate, the problem of patent management, such as more rights, short maintenance and low transfer rate, are becoming more and more prominent. In order to revitalize the university patent and improve the management efficiency effectively, it is urgent to construct university patent evaluation system. This paper is based on the patent value analysis index system designed by the China Technology Exchange, taking creative evaluation, patent evaluation and evaluation system reform as the basic path and with the direction of Innovation oriented transformation, and then the university patent evaluation system was constructed, afterwards the application of evaluation system is discussed with the object of the creative, teacher and student patent management. Under the current Chinese situation, patent evaluation system is beneficial to cultivate innovative atmosphere and enhance the quality of innovation, it also plays an important supporting role in the maintenance and operation of patent rights and the innovation management of students.
\end{abstract}

Keywords: University Patent, Evaluation Model, Application Countermeasures

\section{Introduction}

With the promotion of national intellectual property strategy, the patent work of universities in our country also ushered in an important turning point. In particular, the number of patents has been rapidly increased. Statistics show that during the 12th five-year period, the number of university patent applications has increased by about $20 \%$ each year. However, with the continuous accumulation of the number of patents, due to the deep-seated influence of institutional mechanisms [1-4] and innovation-oriented [5-12], a large number of patent problems are filled in university patents. Colleges and universities have "a lot of rights to maintain short and low transfers" Phenomenon is widespread [13-15]. The large number of patents for these issues led to generally low conversion rates of patent in universities. The issue of patent conversion rate has also become the key problem that affects the patenting work of colleges and universities at present. The problems of accompanying innovation-driven effect and unbalanced input-output of innovative resources are gradually highlighted [16-21]. However, at the same time, we also see that colleges and universities such as Tsinghua University, Zhengzhou University and Southwest Jiaotong University successfully promoted the transfer of some high-value patents to the market after the reform of the corresponding institutions, mechanisms and policies and systems, the universities have certain potential for patent transformation [22-23]. System and mechanism obstacle are the universal problems that universities in our country are confronted with. In the short term, it is very difficult to carry out deep reform. Under the premise that most patents can not meet the needs of the market, how to effectively value the valuable of the patent mining, and through effective management to improve the efficiency of university patent conversion, is the current improvement of the patent conversion rate of colleges and universities in China need to focus on issues to be considered.

Obviously, this problem is also fully recognized at the national level. Since 2010, the State Intellectual Property Office has commissioned the China Technology Exchange Corporation to organize experts to conduct research and design on the index system for the analysis of the value of patents. Since 2012, this set of indicators System has been 
formed and began to promote the application of the pilot nationwide. By 2013, the State Intellectual Property Office started to formulate IPR management standards at the university level, and advocated that IPR management capabilities should be comprehensively promoted through the standardization of IPR management. The hierarchical management of IPRs is an important part of the standard requirements. Starting from 2015, under the guidance of relevant national policies on the transformation of scientific and technological achievements and the reform of institutional mechanisms, many colleges and universities in China have successively carried out pilot projects on the reform of the science and technology system and mechanism focusing on the reform of the patent ownership system so as to promote the reform through deep reform University patent conversion.

To sum up, both in order to enhance the ability of patent management, or to alleviate the system of inadequate supply of patents resulting from the conversion rate is low, including the response to national guidance in the system, standards and technology, the evaluation of university patent management are imminent [24-28]. In particular, compared with the patents of enterprises and individuals, there is a large number of university patents in general, and most of them originate from the subject projects. The innovation of patents is stronger than practicality. All of these characteristics have put forward new requirements for patent evaluation in colleges and universities. To this end, this article will examine existing patent value evaluation methods based on the study designed to meet the actual university patent evaluation methods. By perfecting the patent evaluation mechanism of colleges and universities, improving the patent management ability of colleges and universities and using the patents, the supporting function of university patents on economic and social development can be improved.

\section{Method}

\subsection{An Analysis of Domestic and Foreign Patent Evaluation Practice}

The patent system since its inception, in innovation, plays an important role in supporting economic development. Especially, with the continuous development of economic globalization, in order to promote the economic development of the pattern of patent is spawned patent operation industry. As a prerequisite for patent operation, all kinds of patent operators, including the investment company Institute the technical trading center through the exploration practice to explore suitable for their own development needs of the evaluation system, and achieved good operating results. Such as the United States patent intellectual law from three aspects of market, products, patent investment establishes core patent value indicators, Taiwan Industrial Research Institute and China technology exchange mainly from the technical evaluation, the three dimensions of legal evaluation and market to evaluate the value of the patent, Shanghai Sheng Hua is the focus on the technology, patent, and commercial potential Four aspects are widely used in China. The inventor of the patent pledge appraisal of patent assets, patent transactions, although by CPA professional quality, but which is considered the commercial nature of the patent, with income based assessment tools, from an economic perspective to the patent to the crude price but have to admit that there are imperfections, the problem is to assess the technical characteristics and ignore the legal characteristics of the patent, so it is difficult to response to the real situation. Although the patent patent is regarded as a business tool, is considered to be the technical scheme of the market main body in order to obtain special interests to the public, but the essential attribute patent is the technical characteristics and legal characteristics, technical characteristics and economic characteristics on the legal nature of patent dependent patent, in the absence of law and technology characteristics of patent for evaluation Before the economic characteristics of the patent will be able to draw a conclusion is not comprehensive.

Commissioned the design from the State Intellectual Property Office and is expected to rise for the national standard Chinese technology exchange evaluation index system, index technology, design the three dimensions of law and economy reflects the basic attributes and the evaluation of patent value to [5]. but as colleges and universities, teaching and research is an important foundation for the patent work, therefore, compared with the enterprise, influencing factors of university patent evaluation is more complex, patent evaluation needs more broadly, the patent evaluation system needs to meet the specific needs for the study design.

\subsection{The Key Influence Factors and Demand of Patent Evaluation}

Affected by the traditional planned economy, the transformation of patent in China faces four problems, which is the university patent evaluation key factors work needing to be considered. One is the main purpose of patent creation is not for the market, more is for scientific research. Patents are being used as the fruits of scientific research, project post project tools or Title Review the two is the lack of credentials. Promote the patent conversion power. Compared to the enterprise, university has some demerits such as: the lack of professional personnel of patents in the team, the lack of profit oriented on the target, the lack of mandatory index in the assessment. Three is the distribution part of university patent benefit mechanism is unable to achieve positive incentives. Even some universities pay attention to and improve the distribution ratio the inventor, but ignored the interests of professional teams in this process of transformation, led to the transformation work. The four is the transformation of the patent No one shows any interest in the way To dispel the enthusiasm of colleges and universities. The inventor and patent transfer way for low-end high-end trading license, and even the capital of extreme shares lack, weakened the university patent imagination. The key problem of comprehensive evaluation of domestic and foreign patents and influence the successful practice of patent evaluation, this paper summarizes and analyzes the internal needs of university patent evaluation, as shown in table 1 . 
Table 1. The internal demand of university patent evaluation table.

\begin{tabular}{ll}
\hline order number & Patent evaluation of internal demand \\
\hline 1 & $\begin{array}{l}\text { The evaluation work of university patent patent system reform system, combined with the mechanism of policy reform, or the specimen, } \\
\text { in order to fundamentally solve the problem. } \\
\text { The patent evaluation should be fully integrated with the design of the evaluation system at the national level, to promote the application } \\
\text { for the next step. }\end{array}$ \\
Due to the current situation of university patent, namely a large amount of low quality, establish the evaluation system of patent value is \\
based on the consideration of the management level, rather than the value directly. \\
The patent stock is large, patent operation more urgent needs, the utility of evaluation tools. Higher practicability here refers to the \\
conduct of the evaluation system, convenient and effective. \\
The patent is more, quality is generally low, the requirements of evaluation tools quality oriented higher. Mainly on how to evaluate the \\
existing tools and scientific evaluation mechanism combining problem.
\end{tabular}

\section{The Construction of University Patent Evaluation System Model}

In summary, this paper proposes a general idea to construct the evaluation system of China's colleges and universities patent, namely to China technology exchange patent evaluation index system as the foundation, combined with the successful practice of the existing domestic and foreign patent evaluation, the realistic demand around the university patent evaluation. The specific construction of specific evaluation system model is shown in Figure 1 below, from the model description of content, construct the patent evaluation system is divided into three parts:

\subsection{The Construction of Evaluation System}

The construction of the evaluation system is based on the evaluation index system of patent value China technology exchange design commissioned by the State Intellectual Property Office, the system is in the full study of domestic and foreign patent evaluation form based on the successful practice of the patent right to the enterprise, universities and other different subjects have certain applicability. On the basis of the colleges and universities to carry out improvement of adjustment, not only absorb the advanced experience of the existing evaluation methods, but also conducive to the formation of university evaluation system applied in a wide scope.

\subsection{The Formation Path of Evaluation System}

\subsubsection{Creative Evaluation System}

The formation of university patent evaluation system is divided into three stages. The first is the front-end of patent evaluation, namely creative evaluation. Creativity is an important source of patent formation. At present, countries in advocating the "mass innovation, entrepreneurship", the University as an important area of innovation resources, each year will have a lot of ideas, for this creative evaluation work is an important part of the patent evaluation system. Through the evaluation of the creative idea, patent application, innovation management, not only can effectively save the cost of innovation, improve innovation atmosphere, improve the success rate of innovation, but also conducive to promoting the cultivation of high value of the patent.

According to the evaluation index system of creative design is mainly based on the connotation of creative interpretation. On creative content, many scholars have studied. Suler (1980) explains the creative process from the perspective of cognition, that is a kind of creative thinking process, it is the main concept of the idea of freedom, conceived the new ideas meaningful content to shape. Some other scholars from the usefulness of the product to understand the "creative". Amabile (1988) to study the influence of creative individuals and individual internal factors from the perspective of psychology, reveals the "creative individuals or small groups by working together in the influence of personal novel and useful ideas". Cummings (1996) studies the ideas from the personal characteristics and organizational characteristics with "creative interpretation is the existence of the potential usefulness of the new product development of the organization, idea and the process of". Ford (1995) more from the external macro environment for creative research, that creativity is the subjective judgment of novelty and value of individual and collective achievements. The connotation of the creative combination, the creative value is mainly reflected in two aspects of novelty and usefulness, and from the creative product the market value realization process (Figure 1 below), and the content of intellectual property rights is the key factor to form the core values of creativity, creative content and creative process is not only the market value of the implementation process of continuous improvement, but also the intellectual property increment process. Therefore, the comprehensive evaluation on the value of creativity, mainly comes from the three aspects of novelty. 


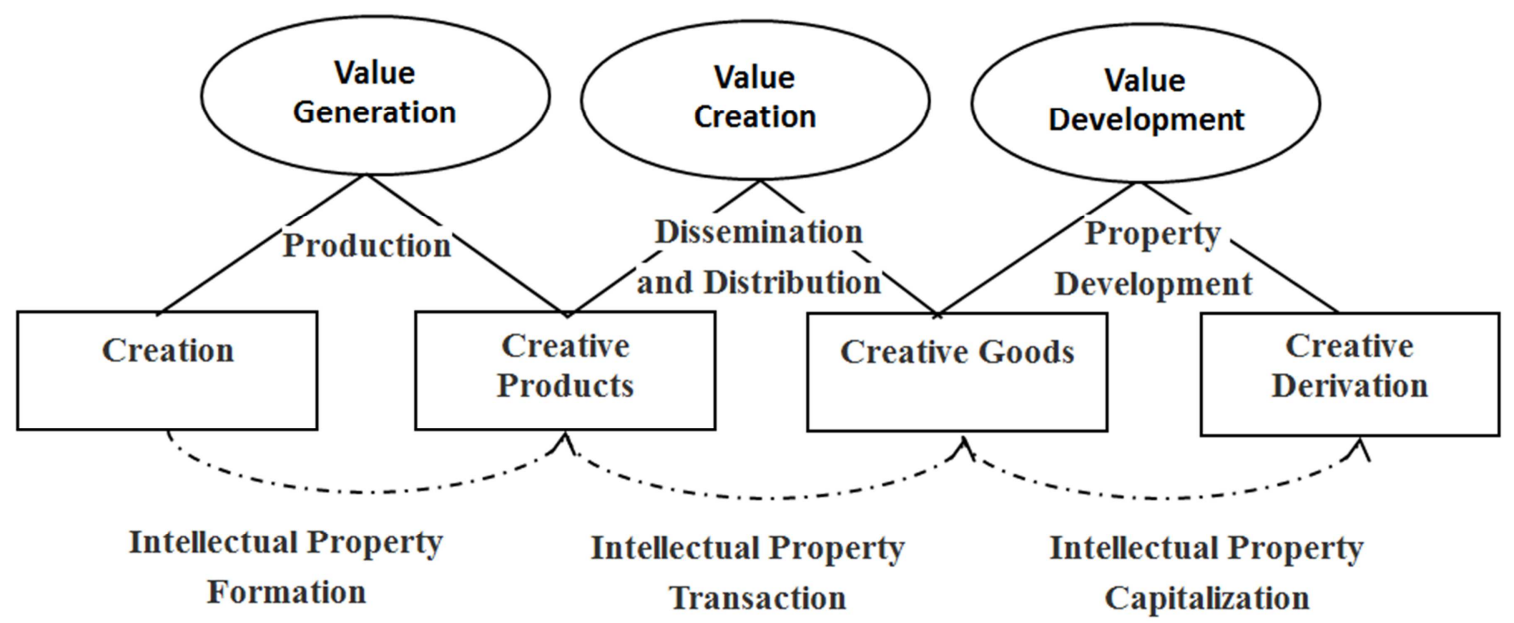

Figure 1. The realization process of market value of creative products.

\subsubsection{Patent Evaluation System}

The second stage is the evaluation system of university patent evaluation. The patent belongs to the invention. The invention mainly comes from teachers or teachers and students with a small part of the patent invention, which is the student independent invention. Therefore, the evaluation of university patent can be divided into teacher evaluation and student evaluation of patent two. The teacher and the students, in the knowledge structure, have differences in innovation experience. The patent evaluation index and the purpose of the evaluation are different across various teachers and students.

Teachers' patent occupies most of the patent, which is the main source of patents or operation. Patent of teachers mainly aim to improve the scientific research oriented innovation, when atmosphere is poor and the patent management or operation of the problem of low efficiency. Students' patent aims to establish the concept of innovation right at the same time, improve the students' innovation management policies of colleges and universities, which might promote students' innovation and entrepreneurship.

The main purpose of teacher evaluation based on patent, design patent evaluation system of teachers is the main Chinese Technology Exchange (hereinafter referred to as "CTeX") patent value evaluation index system as the foundation. There is the large amount of patent evaluation. The management efficiency is low. The operation effect is poor. The problem needs urgent operation premise under the technology of the evaluation system of index adjustment delete, conversion, processing after the final formation. For example, the vast majority of teachers did not study the patent transformation implementation, delete $\mathrm{CTeX}$ patent value evaluation index system in the "economic dimension" of the "market" and "market share" of two indicators evaluated. The number of teachers to patent operability, the "technical dimension" of the "industry trends" into the "technology development trend", through the inspection of the patent In the field of Technology (class IPC classification or large group) nearly five years of patent application growth to reflect the "study"; technical dimension of the "irreplaceable" evaluation index is difficult to replace the "concentration" of the patent, through the investigation and evaluation of the patent for the main classification number the same number of patent evaluation, the greater the degree of agglomeration, show that the technology can the possibility of alternative more patent substitutability is higher.

The main purpose of patent based on the evaluation of students is as follows. Patent itself should be novelty, creativity and practicality. The novel focuses on the students in the process of innovation on the breadth and depth of knowledge, creative students create itself focuses on the difficulty and level of originality cross, technology status and policy adaptability practicability focuses on students' innovation.

\subsubsection{The Integration of Evaluation System and Evaluation System}

The third stage is the fusion of university patent evaluation system and evaluation system of University Science and technology reform. The evaluation system is to improve the patent work performance evaluation system needs to complete a matter of expediency, promote the use of the evaluation system in Colleges and universities of science and technology reform evaluation mechanism, only to realize the organic combination, can play the role of promoting the work of evaluation system the patent into the patent evaluation system. The evaluation system of University Science and technology to the reform process need to get rid of many vested interest obstacles, it is a long-term and arduous task. The specific terms, fusion evaluation system and scientific evaluation system from the evaluation of professional titles, tutor selection, science and technology award, the patent maintenance, awards, innovation business support, security research and other aspects of Bob.

\subsection{The Change of Innovation Orientation}

Get rid of the profound impact of the traditional planned economic system is the key content of the urgent need for the 
patent work in China to achieve the transformation, from the establishment of evaluation system to the scientific evaluation system reform is an important way to solve the problem of innovation oriented universities, and the final evaluation system is to promote the transformation of scientific and technological innovation in universities by scientific research oriented to the market guide. Through the establishment of evaluation system, through the design of evaluation index from the beginning to the final transformation of innovation focus on the implementation of the patent, to a certain extent the weakening of the title assessment project, Innovation Zone Knot Guide of scientific research result.

\section{The Application Countermeasures of University Patent Evaluation System}

\subsection{Creative Evaluation Application}

The university can rely on their academic advantages, actively organize or participate in the technical field of creative activities, or through the construction of innovation platform of online and offline, to raise creative release way, by attracting student groups and social networks to participate in innovation, construction industry patent navigation based on set innovation demand, collaborative innovation, creative the evaluation of IP, creative and creative value chain to achieve full line on-line platform combination, realize innovation chain distribution from the innovation demand to explore the innovation of revenue management. Based on the collected creative evaluation and carry out classification management, carry out special operations management to better meet the patent for creativity. The application conditions of the creative organization, the patent agent and patent operation personnel to follow up, docking. The patent agent responsible for tracking the creative work of patent application In order to ensure the maximum patent protection of creative ideas, the patent operator shall be responsible for the market evaluation of originality or patent, and carry out the external market promotion.

\subsection{The Application of Teacher Patent Evaluation}

\subsubsection{Patent Maintenance Management Applications}

The patent maintenance is the premise of effective patent management and operation of the college has a lot of patents in force, although the patentee, but to maintain the patent right or not is generally weigh the advantages and disadvantages of individual teacher based on the scientific research personnel in Universities in China generally lack the ability of thinking or the market, resulting in a lot of patents remain very short time was abandoned, causing serious loss of intangible assets of colleges and universities. The survey found that the average duration of patent in China is generally low, about 7 years for [29-30], universities can carry out exploration and practice of the patent maintenance actively, combined with teachers' patent evaluation results of different grades of patent maintenance time is put forward suggestions, as the basis of maintaining the patent or not, and actively guide the rational decision of university teachers.

\subsubsection{Application of Patent Operation Management}

To promote the patent operation work, enhance the operational efficiency of patent is an important way to solve the dilemma of the patent work. Facing the increasing patent stock needs the help of effective technical means to realize the patent operation breakthrough. Therefore, universities can combine their academic advantages, a clear focus on technology field, and by carrying out a comprehensive evaluation on Teachers' work the patent, actively carry out targeted patent purchasing work. At the same time, colleges and universities should actively set up or the use of external professional patent operations team, concentrate manpower, material and financial resources to carry out targeted storage of patent licensing, transfer, pledge, technology shares and other external promotion work. In addition, in the process of science and technology patent award, the declaration the project also introduced the patent evaluation.

\subsection{Application of Student Patent Evaluation}

The key lies in the management of students' innovation to guide students to establish a correct concept of innovation, entrepreneurship, college students can actively promote the patent evaluation and students' innovative, entrepreneurial management combined with the national policy guidance, students will patent evaluation management into students' innovation, business credit incentive policy. For the innovation ability of students in innovation venture capital, support site and personnel to be the focus of care, and to develop innovation and entrepreneurship training plan, establish innovative files and transcripts. At the same time, strengthen students' patent evaluation management in the Student Awards, application evaluation work. Students with strong innovation ability, should be considered in the selection of outstanding students, for example, giving priority to graduate students for further study.

\section{Conclusions and Implications}

With many low quality patents and low transformation efficiency in Colleges and Universities, the innovation driven development of Chinese universities is seriously affected. In recent years, China has carried out a series legal system reform to promote the transformation of scientific and technological achievements in Colleges and Universities, but the total effect is general, the reason lies in the depth of the reform did not really hit the assessment system design of University and subject evaluation, the major scientific research fund project and evaluation of professional titles for teachers, the patent quantity advantage has not been effectively transformed into innovative competitive advantage. This paper focuses on University Innovation Evaluation what is the fundamental constraints of patent transformation, from initial idea to patent management, and then to innovation oriented guidance, the basic application path of patent 
evaluation system is discussed systematically, and then, this paper discusses the application strategy of patent evaluation system in Colleges and Universities with the object of the creative, teachers and students' patents, it is of practical significance to optimize the patent management of universities in the current context.

\section{References}

[1] Cheng Deli. Research on operating mechanism of patent technology in Universities [J]. intellectual property, 2014, 07:74-77+91.

[2] Liu Chunlin. Influence factors and improvement measures of legal guarantee of University Patent Transformation [J]. CHINESE UNIVERSITY SCIENCE \& TECHNOLOGY, 2015,(06):55-57.

[3] Yu Bin. Analysis of patent management in Chinese colleges and Universities under the new situation [J]. CHINESE UNIVERSITY SCIENCE \& TECHNOLOGY, 2016, (04):10-12.

[4] Gu Haibo, Zhao Yue. Research on the performance evaluation mechanism of encouraging university patent transformation $[\mathrm{J}]$ CHINESE UNIVERSITY SCIENCE \& TECHNOLOGY, 2016,(05):58-61.

[5] He Qi, Gao Changchun. The Value Characteristics and Composition of Creative Goods-Based on the Market Value Realization [J]. JOURNAL OF BUSINESS ECONOMICS, 2013, 02:83-89.1.

[6] Tang Heng, Zhu Weiwei. The Construction of Patent Operation in Universities [J]. R\&D MANAGEMENT, 2013, 25(01):88-93

[7] Wang Ruimin, Teng Qing, Lu Feifei. The analysis on the factors affecting the transformation of patents in university and the countermeasures [J]. Science Research Management, 2013, 34(03):137-144.

[8] Du Debin, Li Pengfei, Wang Junsong, Ma Yahua. The thoughts and suggestions on reform of appraising system of science and technology of universities in China $[\mathrm{J}]$. China Higher Education, 2013, 01:16-19.

[9] Liu Keqin. On Local Colleges and Universities Boosting the Regional Innovation-Driven Development [J]. Exploring Education Development, 2014, 34(07):23-27.

[10] Wu Jianguo, Zhang Jingqiang, Wang Jiao. A Comparative analysis of Science and Technology Innovation Ability in Colleges and Universities: An Empirical Study Based on Factor analysis [J]. Science \&Technology Progress and Policy, 2016, 33(15):151-155.

[11] Li Chang, Tang Heng, Jin Yucheng, Cheng Long. The Selection Effect Mechanism and Model Research of University Patent Conversion Mode [J]. China Science and Technology Forum, 2016, (04):76-82.

[12] Zhang Jingqiang, Wang Jiao. Science Technology Innovation and Technology Spillover of University and Regional Technology Progress_-Based on Empirical Research of 2002 2014 Data [J]. Journal of Industrial Technologyical Economics, 2017, 36(07):156-160.
[13] He Jianhua, Gao Gangling, He Peng. Analysis on current situation and Development Countermeasures of patent transformation in Chinese colleges and Universities [J]. Science and Technology Management Research, 2009, 29(12):506-507.

[14] Zhao Junfang, Li Guoliang. Research on the Investigation of the Problems of College Students' Patent Activities and the Countermeasures-Based on Statistical Analysis [J]. Research on Higher Engineering education, 2015, 01:45-50.

[15] Sun Yutao, Luan Qian. A 'Three Stages-Two Dimensions' Model of Patent Quality Measuring and Its Empirical Study: A Case Study of C9 League [J]. SCIENCE OF SCIENCE AND MANAGEMENT OF S. \& T, 2016, 37(06):23-32.

[16] Liu Bin, Xie Tingting, Lai Ju. Problems and Countermeasures of patent transformation in Universities [J]. China University of science and technology, 2015, 08:50-51.

[17] Li Yiquan. Evaluation of scientific and technological innovation ability of college internal College from the perspective of innovation driven [J]. JOURNAL OF FUZHOU UNIVERSITY (Philosophy and Social Sciences), 2017, 31(1):34-41.

[18] Sun Jihong, Ma Haiquan. Innovation driven: the source power of University Development [J]. CHINESE UNIVERSITY SCIENCE \& TECHNOLOGY, 2017(9).

[19] Song Xiaozhou. Rational thinking and path selection of colleges and universities to lead the development of support innovation $[\mathrm{J}]$. Journal of the National Institute of Education Administration, 2017(8):65-69.

[20] Xiang Guanghui. Rational thinking and path selection of colleges and universities to lead the development of support innovation $[\mathrm{J}]$. Human Resource Management, 2017(9):161-162.

[21] Zhao liang. The environment construction of the transformation of scientific and technological achievements in Colleges and Universities under the view of the supply side reform $[\mathrm{J}]$. Industry and science and Technology Forum, 2017(21).

[22] Xu Hui. Promoting the transformation of the patent results of the national science and technology program by collaborative innovation of production, learning and research [J]. CHINESE UNIVERSITY SCIENCE \& TECHNOLOGY, 2014(12):24-25.

[23] Wang Jian, Li Yanping. Analysis of the effective mode of University Patent Transformation Based on the transfer of patent rights $[\mathrm{J}]$. China Science and Technology Forum, 2016,(04):70-75+89.

[24] Liang Yan, Wu Xiyao, Zhang Sujuan, Cai Lin. Research on current status, influencing factors and Countermeasures of university patent evaluation [J]. SCIENCE OF SCIENCE AND MANAGEMENT OF S. \& T, 2004, 25(4):48-50.

[25] Li Xiaojuan, Wang Shuanglong, Liang Li, Li Na. Patent classification management method based on patent value analysis system[J]. High technology and industrialization, 2014, 11:92-95.

[26] Liu Wei, Li Xiujuan, Zhao Dangshu, Guo Jiyong. The role of patent technology evaluation in the transformation of scientific and technological achievements [J]. CHINESE UNIVERSITY SCIENCE \& TECHNOLOGY, 2016(9):34-35. 
[27] Dai Xibing, Li Qiaoli, Song Wei. The evaluation of the effectiveness of the quality management of university patent based on background of innovation and entrepreneurship [J]. CHINESE UNIVERSITY SCIENCE \& TECHNOLOGY, 2017(4):42-44.

[28] Guo Jianjun, Sun Xiao. University patent and its classification management based on policy orientation [J]. Consume Guide, 2017(3).
[29] Cai Zhonghua, Hou Aoyu, Ma Huan, Empirical Research on Determinants of Patent Renewal Time [J]. Science and Technology Management Research, 2015, 21:160-163.

[30] Lu Yikai, Zhang Shanjie, Liu Xiaoqin, Chen Weijiong, The Analysis and Advice Research on Patents of Universities in Shanghai Based on Effective Invention Patents [J]. Journal of Modern Information, 2015, 03:91-96+108. 